\title{
A Study to Assess Global Availability of Fetal Surgery for Myelomeningocele
}

Short running title: Global Availability of Fetal Surgery for Myelomeningocele

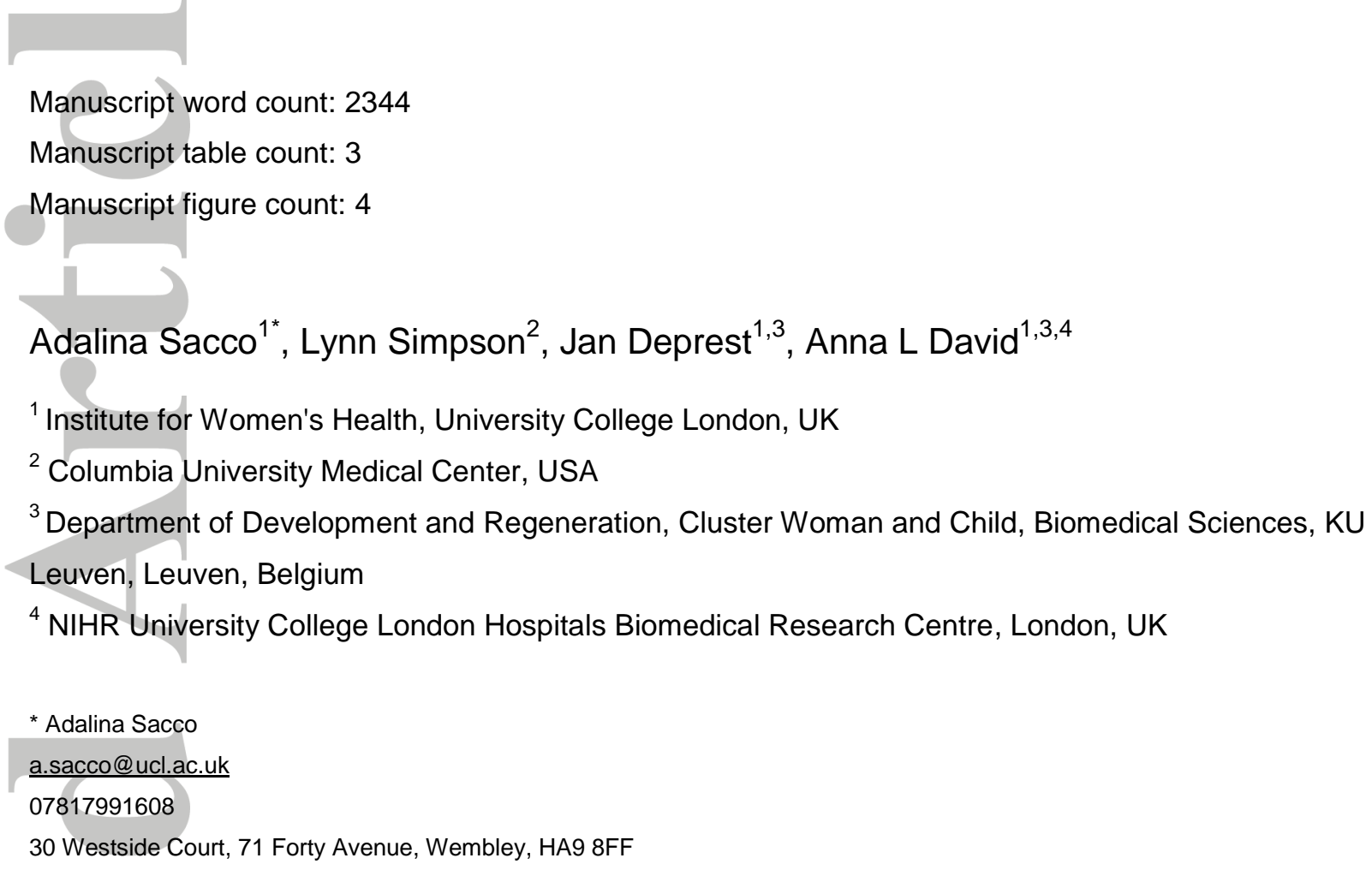

Conflict of interest statement:

All authors report no conflict of interest.

Funding statement:

This study is unfunded.

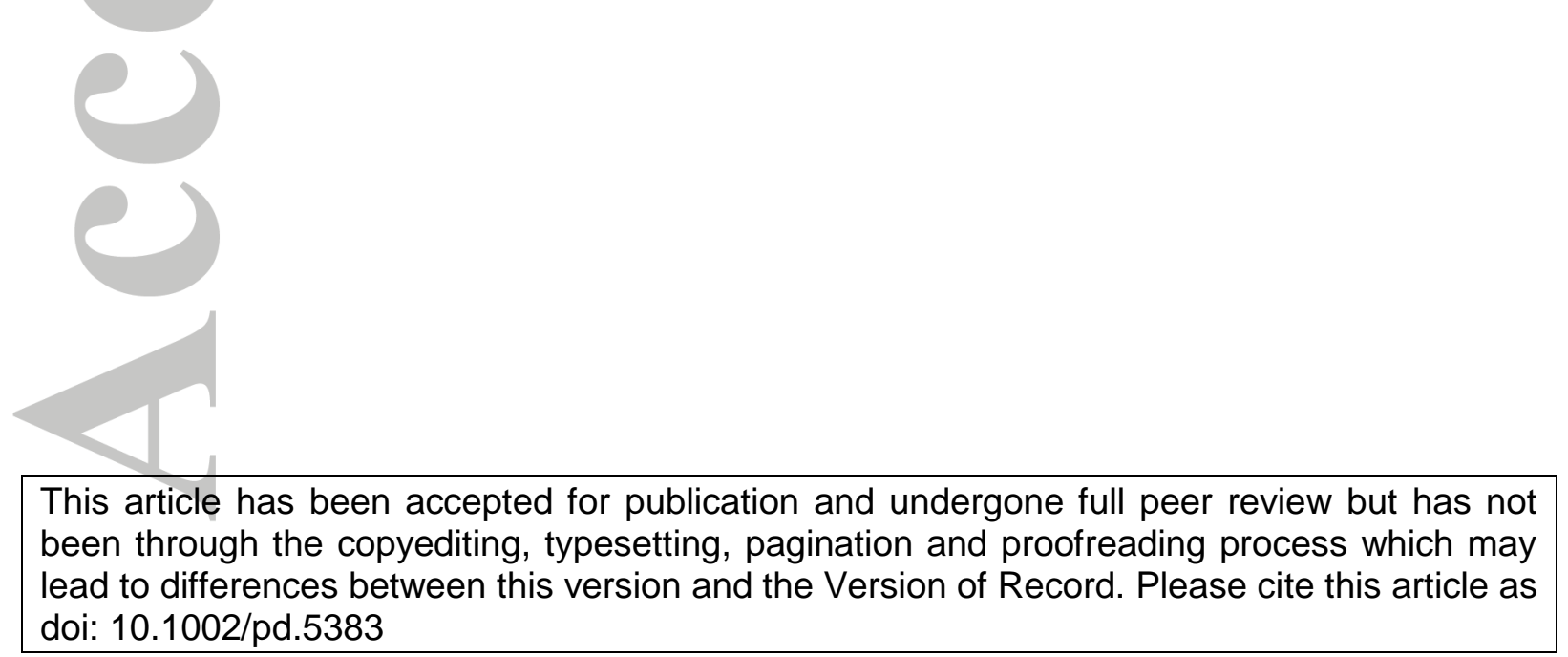


What's already known about this topic?

- The Management of Myelomeningocele Study (MOMS trial) provided level 1 evidence that fetal surgery for myelomeningocele (MMC) improved neonatal outcome compared to postnatal surgery.

- Provision of fetal surgery has expanded since the MOMS trial, but it is unclear how many centres offer fetal MMC closure.

- Various closure techniques have been described, particularly for fetoscopic surgery.

- Case series suggest a broadening of inclusion criteria from those used in the MOMS trial.

What does this study add?

- This study provides a global resource of centres offering fetal surgery for MMC and details of their service.

- Two thirds of centres perform this operation by hysterotomy and the vast majority with patient inclusion criteria based on the level 1 RCT evidence (the MOMS trial).

- A few centres now offer surgery up to 28 weeks of gestation, beyond the MOMS trial inclusion criteria.

- Neurosurgical closure was similar for open surgery but highly variable between centres offering fetoscopy surgery; more data is needed regarding the optimal type of fetoscopic repair and its comparison to open surgery.

This article is protected by copyright. All rights reserved. 


\section{Abstract}

\section{Aim}

To establish the provision of fetal surgery for myelomeningocele (MMC) worldwide.

\section{Methods}

Through the International Society for Prenatal Diagnosis (ISPD) Fetal Therapy

Special Interest Group and the North American Fetal Therapy Network (NAFTNet), fetal therapy centres were surveyed (September 2017-June 2018) regarding availability of fetal MMC surgical repair, patient inclusion criteria, repair techniques, number of cases and outcome reporting. Responses were summarised on an interactive map on the ISPD website.

\section{Results}

44 of 59 centres responded $(74.6 \%)$ of which 34 centres $(77.1 \%)$ currently offered fetal surgery for MMC and 7 centres (15.9\%) were awaiting a first case after service set up. Patient inclusion criteria were similar and based on the Management of Myelomeningocele (MOMS) trial. Five centres (14.7\%) operated beyond 26 weeks' gestational age, outside the MOMS criteria. Open fetal surgery was provided in 23 centres (67.6\%), fetoscopic surgery only in five (14.7\%), and six centres offered both types (17.6\%). Neurosurgical closure was similar for open surgery but highly variable in fetoscopy surgery. The median number of cases per centre was 21 (range 1-253).

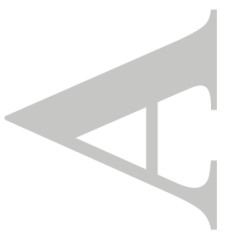




\section{Conclusions}

Fetal surgery for MMC is now offered globally. Two thirds of centres offer open repair via hysterotomy using criteria based on the MOMS trial.

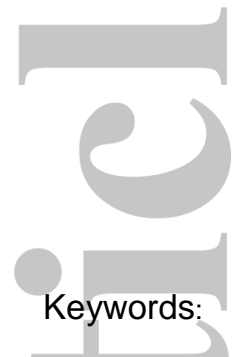

Spina bifida, myelomeningocele, fetal surgery, open fetal surgery, fetoscopy, fetal surgery centre

\section{Acknowledgements:}

ALD is supported by the National Institute for Health Research University College London Hospitals Biomedical Research Centre. We would like to thank Julie Moldenhauer from NAFTNet and Erin Irtenkauf, Alison Cockrell, Lisa Hui, Louise WilkinsHaug and Ignatia Van den Veyver from ISPD for their assistance.

\section{Collaborators:}

Antinolo G, Bahtiyar MO, Belfort M, Blumenfeld Y, Canaz H, Carreras E, Cass DL, Cruz-Martinez R, Elbabaa S, Emery SP, Etchegaray A, Francis K, Gardener G, Goodnight W, Gil-Guevara E, Horzelska E, Jouannic JM, Kohl T, Lapa DA, Lillegard J, Luks FI, Meuli M, Miller J, Moldenhauer J, Moon-Grady AJ, Moron AF, O'Gorman N, Ruano R, Sanin-Blair J, SepulvedaGonzalez G, Seshadri S, Shamshirsaz AA, Shaw SW, Treadwell M, Tsao K, Van Mieghem T, Ventura W, Zaretsky M. 
$\underline{\text { Introduction }}$

The Management of Myelomeningocele Study (MOMS) ${ }^{1}$ provided level 1 evidence that closure of open spina bifida (myelomeningocele, MMC) before birth, as opposed to postnatal surgery, can reduce ventriculoperitoneal shunt requirement and reversal of hindbrain herniation at 12 months and improve motor function at 30 months. This trial was performed in three experienced centres in the United States, namely Nashville, TN, Philadelphia, PA and San Francisco, CA. Following publication of this landmark trial, there was a rapid increase in the number of centres offering fetal surgery for MMC worldwide. In the United States, a survey of 59 fetal care centres conducted in $2014^{2}$ showed that 9 centres were offering this service. As the response rate was under $50 \%$ this is likely to have been an underestimate.

In Western Europe, fetal surgery for MMC was more slowly established. In the preMOMS era the physician's attitude to open fetal surgery, mainly due to its maternal invasiveness, was suggested to be a limiting factor ${ }^{3}{ }^{4}$. Variation in the availability and uptake of pregnancy termination may also play a role in the perceived need for fetal MMC repair ${ }^{5}$. A study in Belgium and Holland in $2014^{6}$ found that over three quarters of patients diagnosed with fetal MMC opted to end the pregnancy. On the other hand fetal surgery for MMC was more rapidly embraced ${ }^{7}$ in some parts of eastern Europe and South America where termination of pregnancy is less of an option, with several South American and one Polish centre offering open fetal surgery for MMC pre-

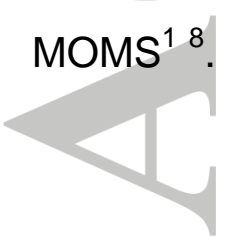


Following its publication, an American College of Obstetricians and Gynecologists Committee Opinion ${ }^{9}$ stated that the outcomes of the MOMS trial were likely to be the "best-case scenario" as the trial was undertaken in a rigorous fashion with strict patient selection and surgery limited to only three centres which already had extensive experience. The committee recommended that fetal surgery for MMC "should only be offered at facilities with expertise in fetal diagnosis and therapy, multidisciplinary teams, services, and facilities to provide the intensive care required for these patients". The MMC Task Force Position Statement ${ }^{10}$ also recommended that fetal MMC repair should be limited to centres with expertise and experience in fetal therapy. It advised that the MOMS protocol should be followed and that modifications were "only permissible after the results of fetal MMC repair performed by an expanded number of centres have been shown to be consistent with the results obtained in the MOMS trial". It was suggested that short and long-term outcome data should be kept in a national registry with periodic review.

A later joint IFMSS and NAFTNet Opinion ${ }^{11}$ also recommended that all centres performing invasive fetal procedures should report their maternal, fetal, and newborn outcomes and that more formalised fetal intervention training should be developed.

It is apparent from conference abstracts and discussions that many other centres worldwide are now offering fetal surgery for MMC, with a variety of inclusion criteria and surgical techniques in use. This has become even more apparent with the introduction of fetoscopic surgery, which to our knowledge does not currently allow a conventional, anatomical multi-layered repair, yet for which multiple surgical techniques exist ${ }^{12} 1314$. Because of the fast-growing number of centres and evolution of techniques, we aimed to map the current practice through a survey to establish 
the provision of fetal surgery for MMC worldwide, to document variations in patient inclusion criteria and surgical techniques at different centres.

\section{Methods}

Through the International Society for Prenatal Diagnosis (ISPD) ${ }^{15}$ Fetal Therapy Special Interest Group and North American Fetal Therapy Network (NAFTNet) ${ }^{16}$, fetal therapy centres offering fetal MMC repair or in preparation for offering this surgery were contacted from September 2017 to June 2018.

Centres were asked to provide the following information via email questionnaire:

- Is fetal surgery for MMC available in your centre/country?

- Who are the lead clinicians for this service?

- Where do your patients come from?

- What criteria do you use when offering surgery?

- What access method is offered (open or fetoscopic)?

- What exact neurosurgical repair techniques are used?

- What is the estimated number of cases performed to date?

- Has your outcome data been published or presented? or any other comments.

The responses were analysed and an interactive map listing all the responding centres was published on the ISPD Fetal Therapy Special Interest Group website ${ }^{17}$. No ethical approval was required for this study as no primary patient data was collected. 
$\underline{\text { Results }}$

Centres Offering Fetal Surgery

Fifty-nine fetal therapy centres were identified as potentially offering fetal MMC surgery (Figure 1), of which contact details were available for 56 centres. Responses were received from 44 centres $(74.6 \%)$. Three centres $(6.8 \%)$ did not have a fetal surgery service and were excluded from further analysis. Thirty-four centres (77.3\%) were performing fetal surgery for MMC and seven centres (15.9\%) had set up a fetal surgery service but were still awaiting a first case (Table 1). Most centres providing or setting up a fetal surgery service were in North America (19/41, 46.3\%) and Europe $(9 / 41,30.0 \%)$.

\section{Patient Criteria}

Most centres reported following the MOMS trial inclusion criteria ${ }^{1}$, modified more recently to allow women with a BMI up to 40 or with one previous Caesarean section. Modifications or alterations to these criteria were reported by eight centres, as follows:

- An upper gestational age limit of 28 weeks' gestation (26 weeks' in MOMS) was reported by four centres (Vall d'Hebron Hospital, Barcelona; Hospital Universitario Austral, Buenos Aires; Hospital Albert Einstein, Sao Paulo and Children's and Women's Specialty Hospital of Queretaro, Mexico) and an upper gestational age limit of 27 weeks' gestation was reported by one centre (Centro Paulista de Medicina Fetal / Hospital e Maternidade Santa Joana / EPM-UNIFESP - São Paulo, Brazil). 
- One centre reported offering fetal surgery up to a BMI of 45 if the placenta was posterior (German Center for Fetal Surgery and Minimally Invasive Therapy, Mannheim).

- A relaxation of the minimum age restriction (18 years in MOMS) and the requirement for US citizenship or residency was reported by two US centres.

- One centre reported that fetal kyphosis greater then $30^{\circ}$ and a short cervix were not used as exclusion criteria (Hospital Albert Einstein, Sao Paulo).

\section{Type of Fetal Surgery Offered}

Figure 2 summarises the types of fetal MMC surgery currently being offered. Most centres performing fetal surgery for MMC were exclusively using open access (laparotomy and hysterotomy) (23/34, 67.6\%). Five centres (Vall d'Hebron Hospital, Spain; Necker-Enfants-Malades, France; German Center for Fetal Surgery and Minimally Invasive Therapy, Germany; Hospital Albert Einstein, Brazil; Medicina Perinatal Alta Especialidad / Unidad de Cirugia Fetal, Monterrey City, Mexico) reported performing only fetoscopic surgery $(5 / 34,14.7 \%)$ and six centres (Texas Children's Hospital, Texas; Mayo Clinic, Minnesota; John Hopkins Center for Fetal Therapy, Baltimore, Instituto Peruano de Medicina y Cirugia Fetal, Peru; Mother and Child Hospital, Iran; Istanbul Bilim University, Istanbul) were performing both open and fetoscopic surgery $(6 / 34,17.6 \%)$.

Three US centres offering fetoscopic surgery were doing so as an experimental therapy under US Food and Drug Administration (FDA) Institutional Review Board (IRB) oversight. Four centres currently providing only open surgery commented that they would be interested in offering a fetoscopic service when further evidence on efficacy and technique was available. 
Access and Neurosurgical Technique of Fetal Surgery by Hysterotomy

Thirty-four centres offering or about to start fetal MMC repair by hysterotomy were identified. Of these, 29 were already performing open fetal surgery (23 open only, six alongside fetoscopic) and five centres were setting up open fetal surgery (three open only, two alongside fetoscopic). Of the 34 centres offering or planning to offer open surgery, 28 were performing or planning to perform a multi-layer repair as described in the MOMS trial ${ }^{1}$ (Figure 3). Two centres reported routinely using a collagen patch between the placode and skin. Four centres did not provide details on their repair technique. Although entry and closure techniques of the hysterotomy were not specifically enquired about, four centres reported using a different uterine entry technique to the auto-stapling device (US Surgical CS-57, Covidien, US) described in MOMS, in order to perform a $6-8 \mathrm{~cm}$ hysterotomy ${ }^{18}{ }^{19}$. Two centres reported using a "mini" (less than $4 \mathrm{~cm}$ ) rather than a wide hysterotomy for uterine access. One centre reported a modified hysterotomy closure technique, using three rather than two layers ${ }^{20}$.

Access and Neurosurgical Technique of Fetoscopic Surgery

Fifteen centres performing or planning to perform fetoscopic MMC repair were identified. Of these 11 were already performing fetoscopic surgery (five fetoscopic only, six alongside open surgery) and four centres were setting up fetoscopic surgery (two fetoscopic only, two alongside open surgery). All centres reported using or planning to use partial amniotic carbon dioxide insufflation ${ }^{21}$. There was variation in uterine access and operative techniques between centres (Table 2). The main fetal neurosurgical repair techniques identified so far, are illustrated in Figure 4. 


\section{Number of Cases}

The centres in this study reported an estimated combined total of 1281 open fetal MMC repairs (as of June 2018) and 373 fetoscopic repairs. The number of cases varied greatly between centres with a median of 21 (range of 1 to 253 , Table 3). A few centres reported performing relatively large numbers of cases, whereas many centres reported performing relatively few cases, resulting in a higher mean number of cases per centre than median.

\section{Outcome Data}

All North American centres reported submitting their outcome data to the NAFTNet registry. Three US centres also reported publication of their results in peer-reviewed journals 222324 , as did five centres outside North America 825262728 . Six centres had presented their outcomes at conferences and a further six were planning to publish or present once their case numbers were sufficiently high. Most centres were therefore either contributing to a database of outcomes, publishing and presenting outcomes or planning to do so. Most centres reported that their outcomes were in line with those in the MOMS trial. One centre performing open surgery reported a "higher premature rupture of membranes rate but lower uterine dehiscence rate" than expected and one centre performing open surgery reported a fetal mortality rate of $10 \%$. 


\section{Discussion}

This survey provides an update on the current global availability of fetal surgery for MMC. It shows that since the publication of the MOMS trial, fetal surgery for MMC has spread rapidly, with some centres now adopting potentially less invasive surgical techniques.

There were a larger number of centres performing fetal surgery for MMC worldwide than has previously been reported ${ }^{29}$, with several additional new centres in the process of setting up, highlighting a continued interest in fetal surgery for MMC. The concentration of MMC fetal surgery cases to a small number of centres to allow for maintenance of surgical skills and development of expertise has previously been suggested $^{10}$, but currently in some parts of the world there is more than one fetal surgery centre within a narrow geographical location. For fetoscopic placental laser coagulation in twin-to-twin transfusion syndrome, centralisation and concentration of cases is associated with better outcomes ${ }^{30}$, and this would also seem logical for other types of fetal surgery. Therefore, it may be the case that in the future, collaboration between local centres is established to overcome the issue of small case number.

Patient inclusion criteria was consistent between centres, with an increased gestational age up to 28 weeks being the most common cause for deviation from the MOMS criteria. Four of the five countries offering surgery at a later gestational age were in Central or South America. There may be a number of reasons for the relaxation of the upper limit on gestational age in these centres. There may be 
variations in antenatal care and difficulties in establishing a diagnosis prior to 24 weeks' gestation or in some centres, surgery may be offered until a later gestation as there is no option of termination of pregnancy. Lastly, it may also be that those centres consider that surgery later in gestation may still be of benefit. Understanding outcomes after surgical repair at these later gestations would be useful for the MMC fetal surgery community to know when counselling couples.

The majority of fetal therapy centres perform MMC repair according to the current best evidence - via open access, and using the technique described in the MOMS trial. However, an interest in less invasive options is clear from this survey, with two centres utilising a mini-hysterotomy for access and a number offering fetoscopic surgery either alone or as an alternative to open repair; more still expressed interest in moving to fetoscopic repair in the future. Repair techniques for fetoscopic surgery vary widely, and more so than for open surgery. Apparently this is still a technique in progress and the optimal surgical technique remains to be defined ${ }^{13}{ }^{14}$. There is currently insufficient evidence to recommend one method of fetoscopic repair to another. The existing heterogeneity also makes it difficult to compare "fetoscopic" outcomes to open, more data is needed to enable comparison.

This study aimed to identify and question fetal therapy centres via their involvement or registration with ISPD and NAFTNet. Although an effort was made to identify other groups, it is likely that there are fetal therapy centres which were not contacted. As both ISPD and NAFTNet have headquarters in the United States, our knowledge may be biased towards western centres with less known about centres in Russia, the Middle East and Africa. Another limitation was the use of self-reporting, which 
remained unverified, and that the data was published online through the ISPD Fetal Therapy Special Interest Group map ${ }^{17}$ which may have influenced responses.

Finally, whilst "outcome data" was enquired about, particular parameters such as gestational age at delivery, shunt rate or mobility, were not requested.

The majority of fetal therapy centres were either contributing to a database of outcomes, publishing and presenting outcomes or planning to do so. However, with the exception of NAFTNet, there is no cross-centre collection of data which could be used for pooling outcomes and furthering knowledge. To this end, the option of a global database could be considered in the future.

\section{$\underline{\text { Conclusion }}$}

Fetal surgery for MMC is now offered globally. Two thirds of centres perform this operation by hysterotomy and the vast majority with patient inclusion criteria based on the MOMS trial. The ISPD interactive map of fetal surgery for MMC may provide a useful resource for clinicians, patients and stakeholders. 


\section{$\underline{\text { References }}$}

1. Adzick NS, Thom EA, Spong CY, et al. A randomized trial of prenatal versus postnatal repair of myelomeningocele. N Engl J Med. 2011;364(11):993-1004. doi:10.1056/NEJMoa1014379.

2. Kett JC, Woodrum DE, Diekema DS. A survey of fetal care centers in the United States. J Neonatal Perinatal Med. 2014;7(2):131-135. doi:10.3233/NPM-14814005.

3. Deprest JA, Flake AW, Gratacos E, et al. The making of fetal surgery. Prenat Diagn. 2010;30(7):653-667. doi:10.1002/pd.2571.

4. Van Calenbergh F, Joyeux L, Deprest J. Maternal-fetal surgery for myelomeningocele: some thoughts on ethical, legal and psychological issues in a Western European situation. Childs Nerv Syst. 2017;33(8):1247-1252.

5. Garne E, Khoshnood B, Loane M, et al. Termination of pregnancy for fetal anomaly after 23 weeks of gestation: a European register-based study. BJOG. 2010;117(6):660-666. doi:10.1111/j.1471-0528.2010.02531.x.

6. Ovaere C, Eggink A, Richter J, et al. Prenatal diagnosis and patient preferences in patients with neural tube defects around the advent of fetal surgery in Belgium and Holland. Fetal Diagn Ther. 2015;37(3):226-234. doi:10.1159/000365214.

7. Koszutski T, Kawalski H, Kudela G, et al. Babies with myelomeningocele in Poland: parents' attitudes on fetal surgery versus termination of pregnancy. Childs Nerv Syst. 2009;25(2):207210. doi:10.1007/s00381-008-0653-1.

8. Zamlynski J, Olejek A, Tomasz K. Comparison of prenatal and postnatal treatments of spina bifida in Poland - a non-randomized, single-center study. J Matern Neonatal Med. 2014;27(14):1409-1417.

9. ACOG Committee Opinion. Maternal-Fetal Surgery for Myelomeningocele. 2017; (Number 720):130:e164-7.

10. Cohen AR, Couto J, Cummings JJ, et al. Position statement on fetal myelomeningocele repair. Am J Obstet Gynecol. 2014;210(2):107-111. doi:10.1016/j.ajog.2013.09.016.

11. Moon-Grady A, Baschat A, Cass D. Fetal Treatment 2017: The Evolution of Fetal Therapy Centers - A Joint Opinion from the International Fetal Medicine and Surgical Society (IFMSS) and the North American Fetal Therapy Network (NAFTNet). Fetal Diagn Ther. 2017;42:241- 
248.

12. Belfort M, Deprest J, Hecher K. Current controversies in prenatal diagnosis 1: in utero therapy for spina bifida is ready for endoscopic repair. Prenat Diagn. 2016;36(13):1161-1166.

13. Joyeux L, Engels AC, Russo FM, et al. Fetoscopic versus Open Repair for Spina Bifida Aperta: A Systematic Review of Outcomes. Fetal Diagn Ther. 2016;39(3):161-171. doi:10.1159/000443498.

14. Kabagambe S, Jensen G, Chen YJ. Fetal Surgery for Myelomeingocele: A Systematic Review and Meta-Analysis of Outcomes in Fetoscopic versus Open Repair. Fetal Diagn Ther. 2017;Epub prior. doi:10.1159/000479505.

15. ISPD Website. https://ispdhome.org.

16. NAFTNet Website. https://www.naftnet.org.

17. ISPD Fetal Surgery Map. https://ispdhome.org/ISPD/SIGs/Fetal_Therapy_Map.aspx.

18. Cavalheiro S, da Costa M, Mendonca J, et al. Antenatal management of fetal neurosurgical diseases. Childs Nerv Syst. 2017;33(7):1125-1141.

19. Botelho R, Imada V, Rodrigues da Costa K, et al. Fetal Myelomeningocele Repair through a Mini-Hysterotomy. Fetal Diagn Ther. 2017;42(1):28-34.

20. Zaretsky M, Liechty K, Galan H, et al. Modified Hysterotomy Closure Technique for Open Fetal Surgery. Fetal Diagn Ther. 2017;[Epub ahea. doi:10.1159/000479683.

21. Kohl T, Tchatcheva K, Weinbach J, et al. Partial amniotic carbon dioxide insufflation (PACl) during minimally invasive fetoscopic surgery: early clinical experience in humans. Surg Endosc. 2010;24(2):432-444. doi:10.1007/s00464-009-0579-z.

22. Belfort MA, Whitehead WE, Shamshirsaz AA, et al. Fetoscopic Open Neural Tube Defect Repair: Development and Refinement of a Two-Port, Carbon Dioxide Insufflation Technique. Obstet Gynecol. 2017;129(4):734-743. doi:10.1097/AOG.0000000000001941.

23. Moldenhauer JS, Soni S, Rintoul NE, et al. Fetal myelomeningocele repair: the post-MOMS experience at the Children's Hospital of Philadelphia. Fetal Diagn Ther. 2015;37(3):235-240. doi:10.1159/000365353.

24. Elbabaa SK, Gildehaus AM, Pierson MJ, et al. First 60 Fetal In-Utero Myelomeningocele Repairs at Saint Louis Fetal Care Institute in the Post-Moms Trial Era: Hydrocephalus Treatment Outcomes (Endoscopic Third Ventriculostomy Versus Ventriculo-Peritoneal Shunt). 
Childs Nerv Syst. 2017;33(7):1157-1168.

25. Pedreira DAL, Zanon N, Nishikuni K, et al. Endoscopic surgery for the antenatal treatment of myelomeningocele: the CECAM trial. Am J Obstet Gynecol. 2016;214(1):111. doi:10.1016/j.ajog.2015.09.065.

26. Kohl T. Percutaneous minimally invasive fetoscopic surgery for spina bifida aperta. Part l: surgical technique and perioperative outcome. Ultrasound Obstet Gynecol. 2014;44(5):515524. doi:10.1002/uog.13430.

27. Meuli M, Moehrlen U, Flake A, et al. Fetal surgery in Zurich: key features of our first open in utero repair of myelomeningocele. Eur J Pediatr Surg. 2013;23(6):494-498. doi:10.1055/s$0032-1329700$.

28. Moron A, Barbosa M, Milani $\mathrm{H}$, et al. Perinatal outcomes after open fetal surgery for myelomeningocele repair: a retrospective cohort study. BJOG An Int J Obstet Gynaecol. 2018;[Epub ahea. doi:10.1111/1471-0528.15312.

29. Meuli M, Moehrlen U. Fetal surgery for myelomeningocele is effective: a critical look at the whys. Pediatr Surg Int. 2014;30(7):689-697. doi:10.1007/s00383-014-3524-8.

30. Morris RK, Selman TJ, Harbidge A, et al. Fetoscopic laser coagulation for severe twin-to-twin transfusion syndrome: factors influencing perinatal outcome, learning curve of the procedure and lessons for new centres. BJOG. 2010;117(11):1350-1357. doi:10.1111/j.1471 0528.2010.02680.x.

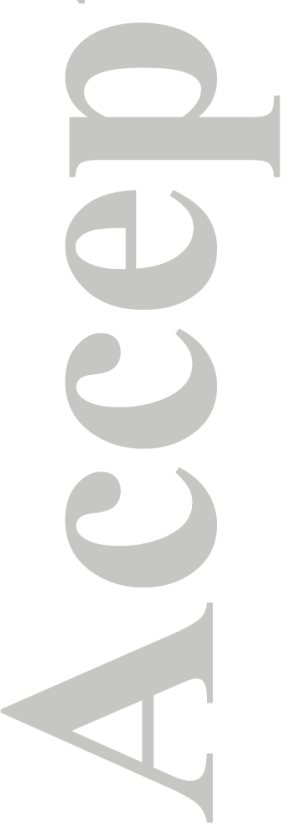




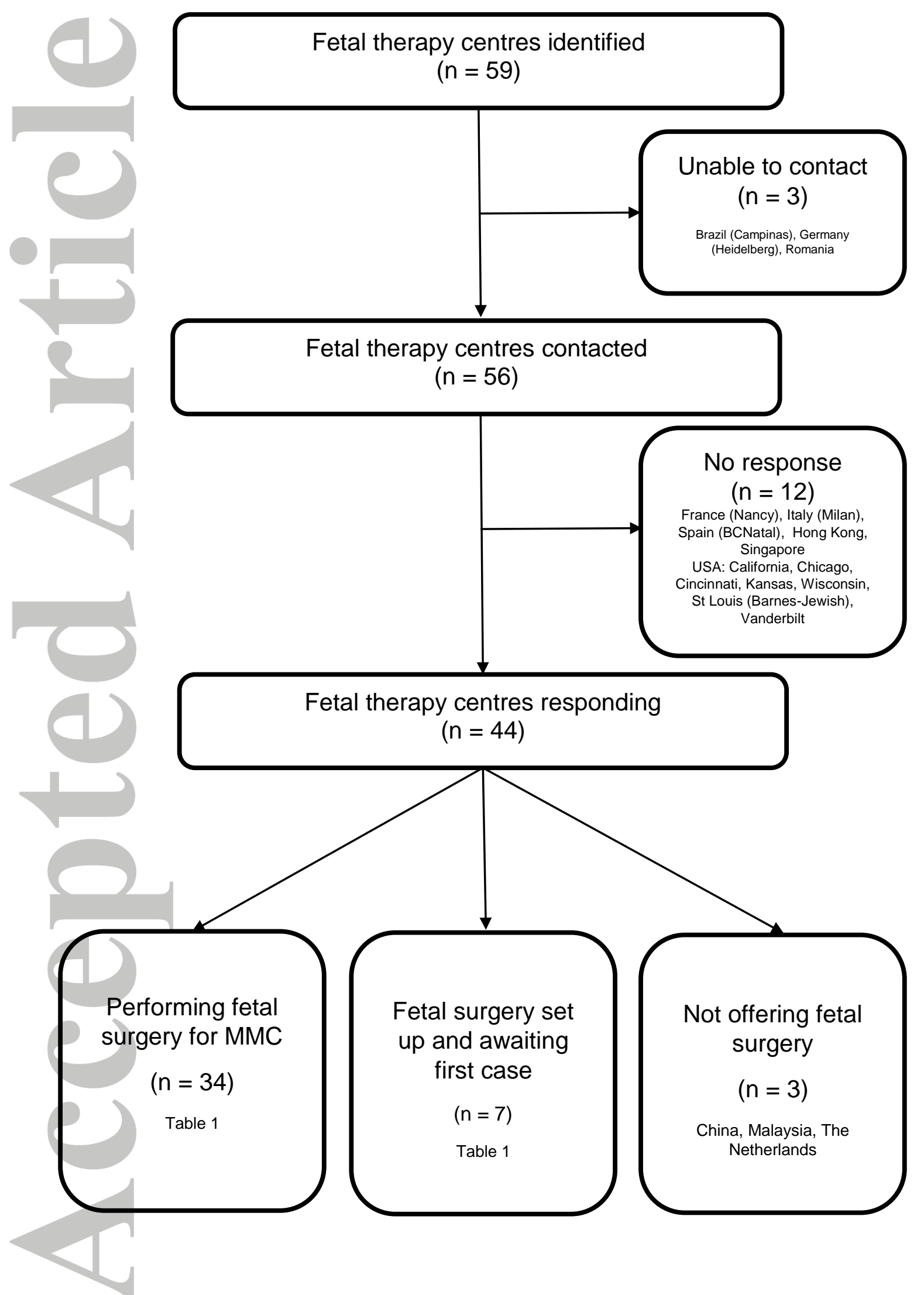

Figure 1: Questionnaire responses and availability of fetal surgery. 


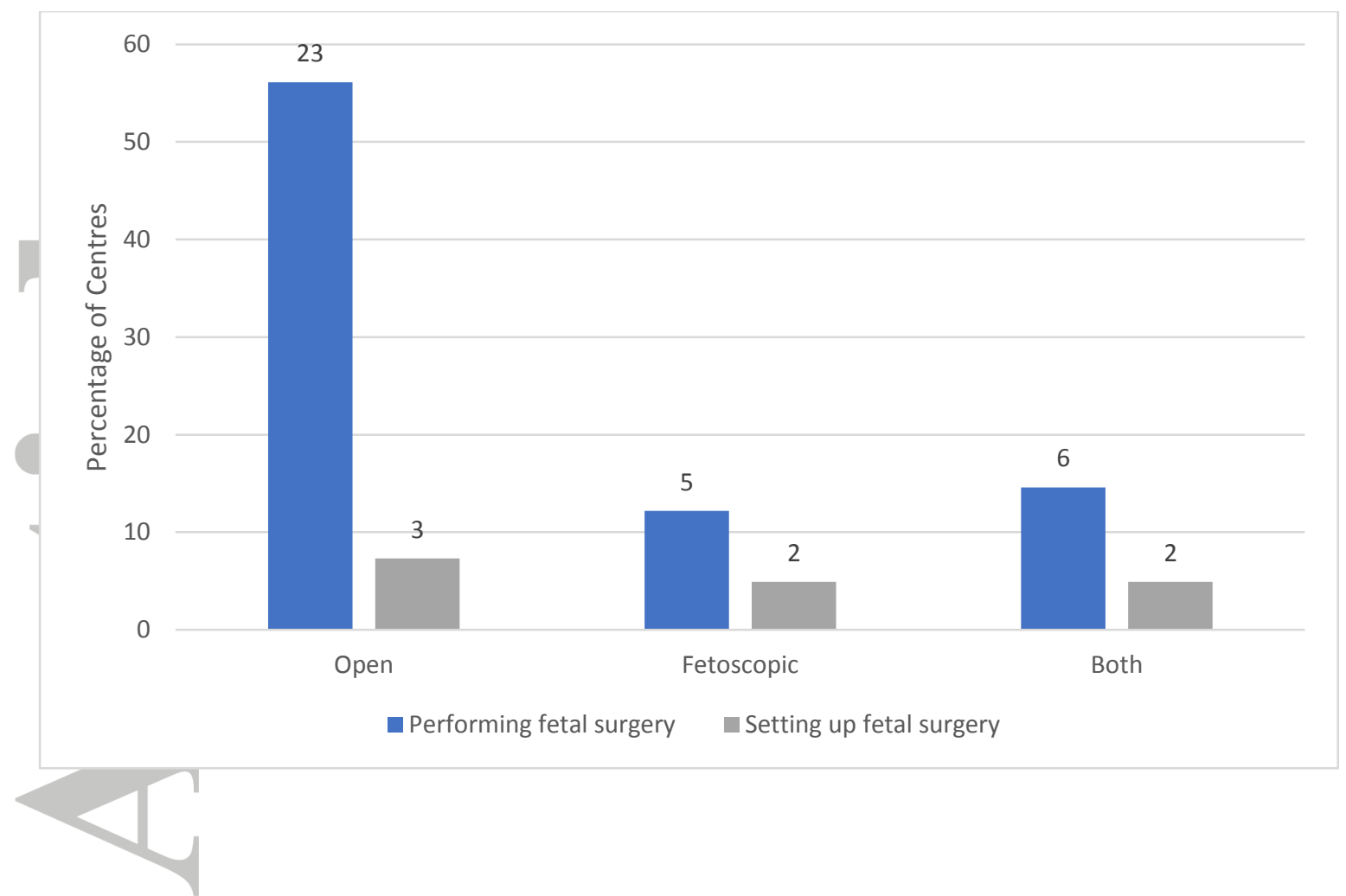

Figure 2: Type of fetal surgery for MMC offered or considered by the respondents.

Expressed as a percentage of centres providing a surgery service; absolute number of centres is displayed above each bar. 


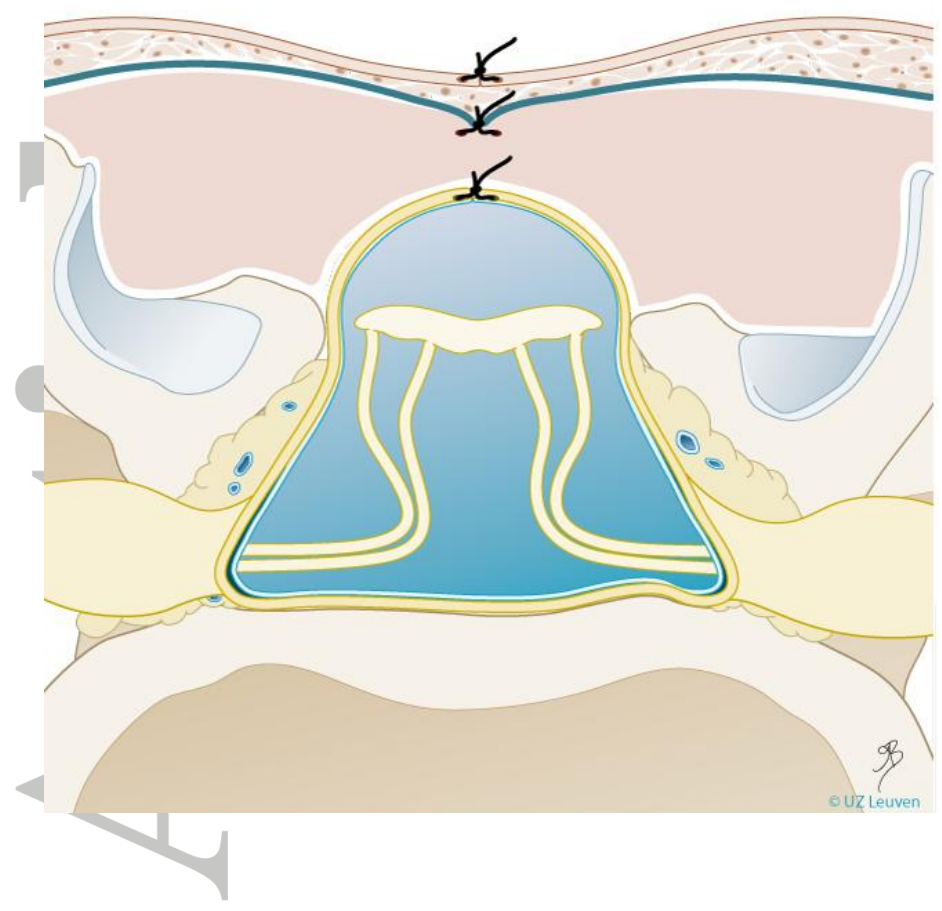

Figure 3: Schematic representation of a three-layer closure technique as typically used in open MMC repair.

Drawing Myrthe Boymans, reproduced with permission of UZ Leuven.

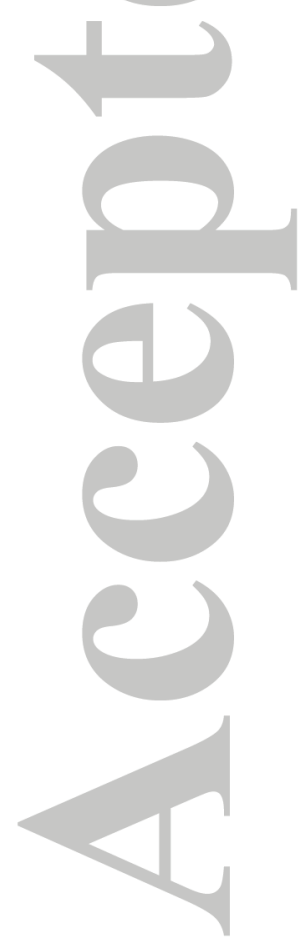

This article is protected by copyright. All rights reserved. 

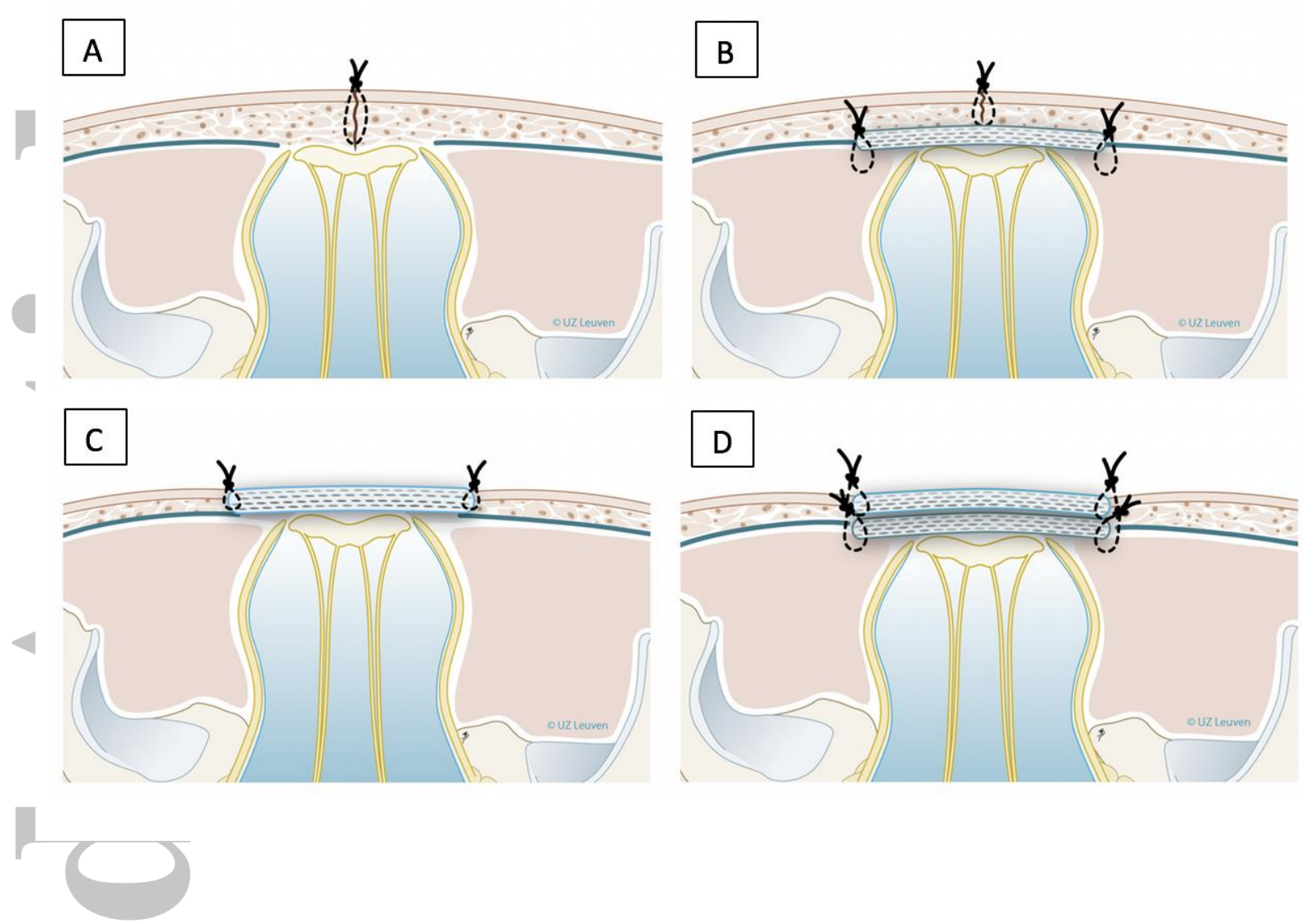

Figure 4: Schematic drawing of neurosurgical repair techniques reported in fetoscopic MMC repair. A:

Single layer repair (skin sutured). B: Double layer repair (subcutaneous patch and skin suture). C:

Patch coverage. D: Double patch repair.

Drawings Myrthe Boymans; reproduced with permission of UZ Leuven, Belgium.

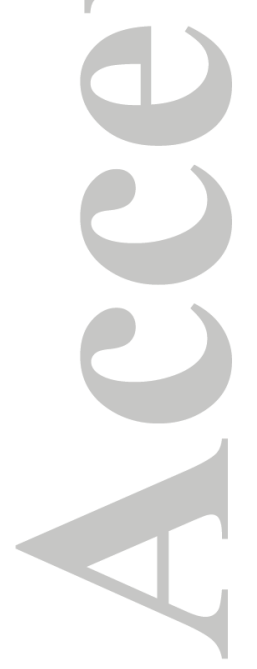


Table 1: Fetal therapy centres offering fetal surgery for MMC.

\begin{tabular}{|c|c|c|}
\hline North America & Europe & South and Central America \\
\hline California & Belgium & Argentina \\
\hline UCSF Fetal Treatment Center, San Francisco & Universitaire Ziekenhuizen (UZ) Leuven & Hospital Universitario Austral, Pilar, Buenos Aires \\
\hline California* & France & Brazil \\
\hline Lucile Packard Children's Hospital, Stanford & Armand Trousseau Hospital, Paris & Hospital Albert Einstein, Sao Paulo \\
\hline Canada & France & Brazil \\
\hline $\begin{array}{l}\text { Mount Sinai Hospital and Hospital for Sick } \\
\text { Children, Toronto }\end{array}$ & Necker-Enfants-Malades Hospital, Paris & $\begin{array}{l}\text { Centro Paulista de Medicina Fetal / Hospital e } \\
\text { Maternidade Santa Joana, São Paulo }\end{array}$ \\
\hline Colorado & Germany & Colombia \\
\hline Colorado Fetal Care Center, Aurora & $\begin{array}{l}\text { German Center for Fetal Surgery and } \\
\text { Minimally Invasive Therapy, Mannheim }\end{array}$ & $\begin{array}{l}\text { Clinica Universitaria, Universidad Pontificia } \\
\text { Bolivariana, Medellin }\end{array}$ \\
\hline Connecticut $^{\star}$ & Poland & Mexico \\
\hline Yale Fetal Care Center, New Haven, Connecticut & Fetal Surgery Center, Bytom & $\begin{array}{l}\text { Department of Fetal Surgery, Children's and } \\
\text { Women's Specialty Hospital of Queretaro }\end{array}$ \\
\hline Florida & Spain & Mexico \\
\hline $\begin{array}{l}\text { Arnold Palmer Hospital for Children, Orlando, } \\
\text { Florida }\end{array}$ & Vall d'Hebron Hospital, Barcelona & $\begin{array}{l}\text { Medicina Perinatal Alta Especialidad, Unidad } \\
\text { Cirugía Fetal Hospital Christus Muguerza Alta } \\
\text { Especialidad, Monterrey N.L. México }\end{array}$ \\
\hline Maryland & Spain & Peru \\
\hline John Hopkins Center for Fetal Therapy, Baltimore & $\begin{array}{l}\text { Department of Maternofetal Medicine, } \\
\text { Genetics and Reproduction, University } \\
\text { Hospital Virgen del Rocío, Sevilla }\end{array}$ & $\begin{array}{l}\text { Fetal Medicine Unit, Instituto Nacional Materno } \\
\text { Perinatal, Lima }\end{array}$ \\
\hline Michigan & Switzerland & Peru \\
\hline $\begin{array}{l}\text { Fetal Diagnostic and Treatment Center, University } \\
\text { of Michigan, Ann Arbor }\end{array}$ & Zurich Center for Fetal Diagnosis and Therapy & $\begin{array}{l}\text { Fetal Medicine Unit, Clinica Angloamericana / } \\
\text { Instituto Peruano de Medicina y Cirugia Fetal }\end{array}$ \\
\hline Minnesota & United Kingdom & \\
\hline Mayo Clinic, Rochester & University College London Hospital, London & Others \\
\hline Minnesota & & Australia \\
\hline Midwest Fetal Care Center, Minneapolis & & $\begin{array}{l}\text { Mater Centre for Maternal Fetal Medicine, } \\
\text { Brisbane }\end{array}$ \\
\hline Missouri & & India* \\
\hline St Louis Fetal Care Institute, St Louis & & Amrita Institute of Medical Science, Kochi \\
\hline New York* & & Iran \\
\hline $\begin{array}{l}\text { Columbia University Medical Center, New York } \\
\text { City }\end{array}$ & & Mother and Child Hospital, Shiraz \\
\hline North Carolina & & Taiwan* \\
\hline $\begin{array}{l}\text { University of North Carolina School of Medicine } \\
\text { Fetal Care Program, Chapel Hill }\end{array}$ & & Chang Gung Memorial Hospital, Taipei, Taiwan \\
\hline
\end{tabular}

This article is protected by copyright. All rights reserved. 


\section{Ohio*}

Cleveland Clinic Fetal Center, Cleveland, Ohio

Pennsylvania

Center for Fetal Diagnosis and Treatment,

Children's Hospital of Philadelphia

Pennsylvania*

Magee-Womens Hospital of University of

Pittsburgh Medical Center (UPMC)

\section{Rhode Island}

Fetal Treatment Program of New England,

Providence, Rhode Island

\section{Texas}

Texas Children's Fetal Center at Texas Children's Hospital, Houston

Texas

University of Texas Health Center at Houston

\section{Turkey}

Istanbul Bilim University, Istanbul

${ }^{*}$ Centres starting programs who have not performed their first case as of June 2018

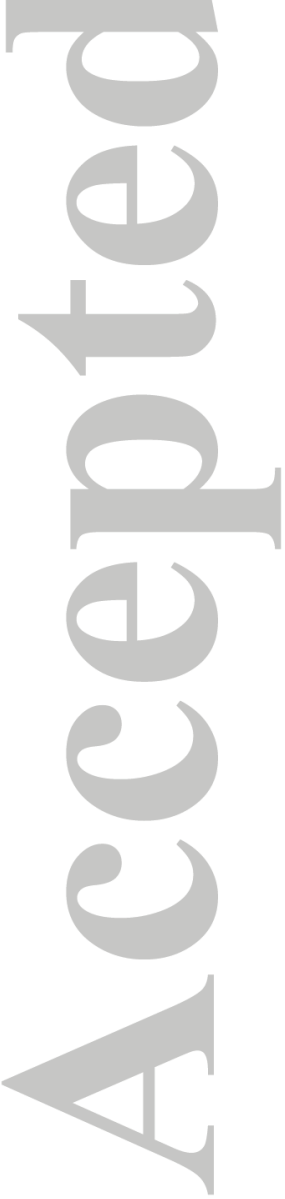

This article is protected by copyright. All rights reserved. 
Table 2: Details on surgical techniques of fetoscopic surgery as reported by individual centres.

\begin{tabular}{|c|c|c|c|c|c|}
\hline $\begin{array}{l}\text { Used by/ planned to be } \\
\text { used by: } \\
\text { Technique: }\end{array}$ & $\begin{array}{l}\text { Texas }^{22}, \text { Baltimore, } \\
\text { Stanford, Iran, Peru }\end{array}$ & $\begin{array}{l}\text { Brazil }^{23} \text {, Taiwan, } \\
\text { New York }\end{array}$ & Germany $^{242526}$, Turkey & $\begin{array}{l}\text { Barcelona, } \\
\text { Mexico }\end{array}$ & Paris \\
\hline Access to the uterus & Exteriorised & Percutaneous & Percutaneous & Exteriorised & Exteriorised \\
\hline Ports & & 3 & 3 & 3 & 2 \\
\hline Patch & Collagen & Biocellulose & Collagen & None & Biocellulose \\
\hline $\begin{array}{l}\text { Neurosurgical } \\
\text { technique (as shown } \\
\text { in Figure 4) }\end{array}$ & Dura and skin (B) & $\begin{array}{l}\text { Skin if possible; if not } \\
\text { 2nd patch (Integra®) } \\
\text { (B or D) }\end{array}$ & $\begin{array}{l}\text { None or second patch } \\
\left(\text { Teflon }^{\mathrm{TM}}\right) \text {. } \\
\text { Some cases: primary skin } \\
\text { closure, no patch (C or D) }\end{array}$ & Skin $(A)$ & Skin (B) \\
\hline
\end{tabular}

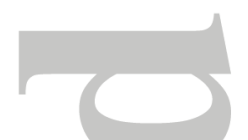

Table 3: Numbers of cases per centre.

\begin{tabular}{|l|c|c|}
\hline & Median & Mean \\
\hline All centres & 21.5 & 51.7 \\
\hline Open & 21.5 & 21.5 \\
\hline Fetoscopic & 8.0 & 53.2 \\
\hline North America & 51.0 & 56.1 \\
\hline Europe & 36.0 & 41.5 \\
\hline Centres outside North America & 8.0 & \\
\hline and Europe & & \\
\hline
\end{tabular}

